\title{
Eating behavior: Social facilitation or social inhibition?
}

HARRY P. SHELLEY

UNIVERSITY OF NEBRASKA

\begin{abstract}
Abstraet
Contrary to the social facilitation studies group reared Ss eat less than singly reared Ss when (1) in a group cage, (2) when caged singly, and (3) when in activity cages. The social facilitation effect may be a product of a once a day feeding schedule as contrasted with the ad lib feeding of the present study.
\end{abstract}

\section{Problem}

There is general agreement on the social facilitation of eating, i.e., animals eat more when eating together than when eating alone (Smith \& Ross, 1952; James, 1960; Zajonc, 1965). Contrary to what would be expected from the social facilitation effect, group reared Ss consistently weigh less than socially isolated Ss. Weight differences could result from the group Ss eating less because they are distracted by the other animals or from the socially isolated Ss eating more because there is little else to do (Premack \& Premack, 1963).

\section{Method}

Subject and Apparatus.

At weaning male Sprague-Dawley rats were placed in 38 in by 12 in by 12 in cages. Experiment I utilized 16 isolated, 16 paired and two group cages of 10 animals. Experiment II used 16 isolated, 16 paired and three group cages of 8,8 , and 6 animals. Experiment III used 24 isolated and two group cages of 8 animals. Eating and drinking was ad lib.

Procedure.

Food consumption. At the end of each $24 \mathrm{hr}$. the paper under the floor of each cage was dried, the fecal boli removed, and dust and particles of food were weighed, added to the weight of the food left in the cage and the total subtracted from the weight of the intact food initially placed in the cage. Considerable food was always present.

Experiment I. From weaning to 98 days of age Ss simply lived singly, in pairs or in a group.

Experiment II. Food consumption was measured for two periods: ages 37 to 39 days and 58 to 61 days。 Data on food dropping were obtained during days 58 to 61 .

Experiment III. At 49 days age 8 isolated Ss were placed in activity cages, 8 in new cages, and 8 left in their original cages. Eight group reared Ss were placed in activity cages and 8 in single cages. Measures of food consumption and food dropping were obtained for 20 successive days. From day 11 to day 20 access to the activity wheel was blocked.

\section{Results}

Weight. The differences in Table 1 are reliable by the end of the first week (Experiment I, $F=3.40$,
TABLE I Mean body weight (grams) and social rearing conditions.

\begin{tabular}{cccccccc} 
& \multicolumn{3}{c}{ Experiment I } & \multicolumn{3}{c}{ Experiment II } \\
\hline Age & Single & Pair & Group & Age & Single & Pair & Group \\
\hline & $(\mathrm{N}=16)$ & $(\mathrm{N}=16)$ & $(\mathrm{N}=20)$ & & $(\mathrm{N}=16)$ & $(\mathrm{N}=16)$ & $(\mathrm{N}=22)$ \\
24 & 64.0 & 63.2 & 65.2 & 22 & 49.4 & 48.9 & 49.1 \\
32 & 110.3 & 106.8 & 99.8 & 29 & 91.5 & 88.5 & 81.6 \\
42 & 186.5 & 185.9 & 175.4 & 43 & 193.2 & 181.5 & 168.9 \\
62 & 290.3 & 291.0 & 272.7 & 62 & 259.8 & 246.4 & 236.5 \\
86 & 388.1 & 379.9 & 367.5 & 79 & 345.8 & 333.4 & 321.9 \\
98 & 410.8 & 414.3 & 393.5 & 131 & 477.6 & 470.4 & 448.3 \\
\hline
\end{tabular}

$\mathrm{df}=2 / 49, \mathrm{p}<.05 ;$ Experiment II, $\mathrm{F}=12.99, \mathrm{df}=2 / 51$, $\mathrm{p}<.01$ )

Food consumption. The data on food consumption and food dropping from Experiment II (Fig。1) provide no measure of individual differences for the paired or group Ss so the usual t-test could not be used. A conservative alternative is to (1) from the t-distributtion establish the $99 \%$ confidence limits about the mean for the socially isolated Ss, and (2) take the confidence limit closest to the group mean and again using the $\mathrm{SE}_{\mathrm{m}}$ for the socially isolated $\mathrm{Ss}$, determine the probability of the mean for the group ss coming from a distribution of means having as a mean the lower limit of the $99 \%$ confidence interval. Since it was the primary focus of attention, only the group vs singly reared comparisons were made. Group Ss eat less food per day, averaging $80 \%$ as much food as the singly reared Ss. For age 37-39 days $\mathrm{SD}_{\text {isolated }}=1.28, \mathrm{t}=13.61$, $\mathrm{df}=15, \mathrm{p}<.001$; for age 58-61 days $\mathrm{SD}_{\text {isolated }}=2.27$, $\mathrm{t}=6.47, \mathrm{df}=15, \mathrm{p}<.001$.

Analysis of variance and orthogonal comparisons were applied to the data in Fig. 2. Under identical living conditions the group Ss continue to eat less food than the isolated Ss. (For days 1 to 10 in the activity

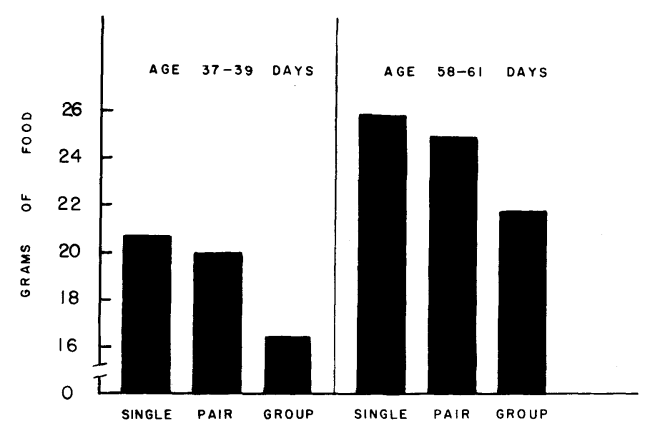

Fig. 1. Experiment II. Mean daily food consumption under varied social rearing conditions. 


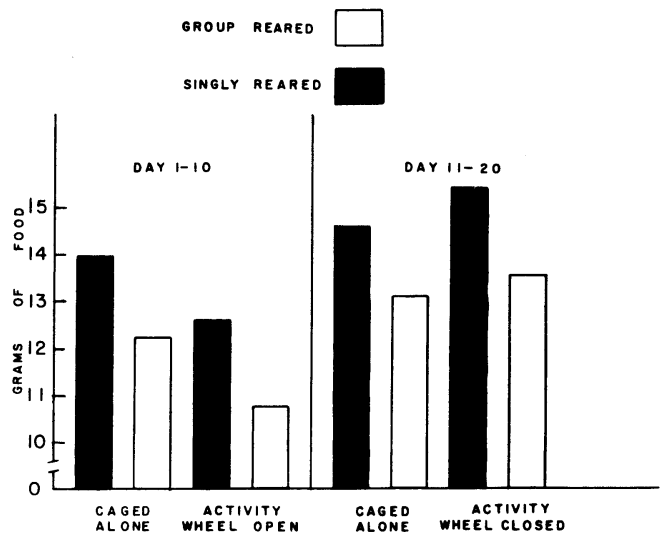

Fig. 2. Experiment III. Mean daily food consumption as a function of social rearing and current cage conditions.

cages $\mathrm{F}=8.94, \mathrm{df}=1 / 35, \mathrm{p}<.01$; in the single cages $\mathrm{F}=8.05, \mathrm{df}=1 / 35, \mathrm{p}<.01$ ) On days 11 to 20 the differences persist; for the locked activity cages $F=14.00$, $\mathrm{df}=1 / 35, \mathrm{p}<.01$; in the single cages $\mathrm{F}=8.67, \mathrm{df}=1 / 35$, $\mathrm{p}<.01$. The activity effect (Premack \& Premack, 1963) is also present, i.e., regardless of rearing conditions, Ss in unlocked activity wheels eat less food than Ss in single cages $(F=9.87, d f=1 / 35, p<.01)$. When activity is precluded, the difference in eating behavior disappears $(F=1.22, \mathrm{df}=1 / 35, \mathrm{p}>.05)$.

Food dropped. In Experiment II socially isolated Ss dropped significantly less food through their cage floor (group mean $=4.41$, single mean $=2.73, \mathrm{SD}_{\text {single }}=$ 1.01, $t=3.87, \mathrm{df}=15, \mathrm{p}<.01$ ). In Experiment III only rarely was a piece of food dropped through the floor of the activity cages due to the small gauge screening on the floors. In the single cages no reliable differences in food dropping as a function of social rearing conditions are present $(F<1.00)$. Dropping of pieces of food occurs in a greater degree when other animals are present.
Evidently social living results in considerable interruption of eating behavior.

\section{Diseussion}

The weight differences associated with post-weaning social living conditions are clearly mediated by behavioral differences in food consumption. The food dropping data indicates the role of distraction; the activity cage data the role of activity. Clearly, too, social facilitation is not associated with ad lib eating behavior. Although James (1960) has shown that social facilitation in puppies requires a period of eating together, group living (and eating) also leads to the opposite state of affairs. The key to the contradiction probably lies in the conditions under which eating occurs, i.e., ad lib eating as compared to a once a day schedule. The higher levels of drive under a deprivation schedule tend to preclude the effects of other drives, e.g., curiosity, and to reduce the effectiveness of stimuli eliciting such behavior as all animals are eating vigorously and making few irrelevant responses. Despite arrangements to eliminate competition the once a day schedule may still elicit competitive responses. Indeed competition may be the very responses learned by James' puppies.

Although a product of 28 days of immediate postweaning living conditions, the differences in eating show remarkable persistence and extensive generalization, extending over both a 20 day period and markedly different conditions.

\section{References}

James, W. T. The development of social facilitation of eating in puppies. J. genet. Psychol., 1960, 96, 123-127.

Premack, D., \& Premack, A. J. Increased eating in rats deprived of running. J. exp. Anal. Behav., 1963, 6, 209-212.

Smith, W. I., \& Ross, S. The social behavior of vertebrates. Psychol. Bull., 1952, 49, 598-627.

Zajonc, R. B. Social facilitation. Science, 1965, 149, 269-274. Note

1. This research was supported by N.I.M.H. Research Grant MH0703102. A portion of the paper was presented at the annual meeting of the Midwestern Psychological Association, May, 1964. 